\title{
CORRESPONDENCE
}

\section{An unusual cause of post traumatic cerebrospinal fluid rhinorrhoea}

\section{Indu Kapoor, Gaurav Singh Tomar, Suman Sokhal}

We report a case of 38-year-old male diagnosed as a case of cerebrospinal fluid (CSF) rhinorrhoea scheduled for anterior cranial fossa repair. He was apparently well few days back, when he met with an accident and had transient loss of consciousness followed by seizures and bleeding from ear, nose, and throat. However, his Glasgow coma score was 15 immediately after this transient episode. The following day he complained of a watery discharge from his left nostril. He was managed conservatively in a private hospital. A Ryle's tube was inserted through the nose but was removed the following day since it was not patent. Fifteen days later, he developed meningitis, for which he received the treatment for next 1 month. During his present admission, he presented with complaint of frank watery discharge from nose, nearly 70 days after trauma, along with headache, high-grade fever $\left(101-102^{\circ} \mathrm{F}\right)$ and nausea. The headache was sudden in onset, precipitated by cough and bending forward. On examination, his general condition was good, and his vitals were stable. The magnetic resonance image showed a $13-\mathrm{cm}$ long tract with surrounding haemorrhage, oedema, and intense enhancement extending from the left side of the nostril to the left high para-median brain parenchyma, through the skull base and ethmoidal sinus with extension above the level of corpus callosum [Figure 1].

A day before surgery, he was advised to take the night dose of anticonvulsant drug (Tab Eptoin $300 \mathrm{mg}$ ). General anaesthesia was induced with fentanyl $100 \mathrm{mcg}$, propofol $100 \mathrm{mg}$, and rocuronium $60 \mathrm{mg}$. Intraoperative finding was suggestive of a wooden foreign body embedded in the brain tissue. This hard tube-like structure was then cut into small pieces as it was difficult to remove en mass. The foreign body was identified as a small bamboo stick [Figure 2]. While cutting the stick by using scissors, a bout of pus oozed out of the stick, which could possibly be the reason for the febrile episodes. The surgical field was instilled with $320 \mathrm{mg}$ of gentamycin. At the end of the surgery, there was considerable brain bulge despite all corrective measures. The postoperative computed tomographic (CT) scan showed a large pneumocephalus. The trachea was extubated on $1^{\text {st }}$ postoperative day since repeat CT scan showed no significant finding.

CSF rhinorrhoea is defined as a rare medical condition in which the CSF fluid that normally cushions the brain and spinal cord runs from the nose. Several incidents may inadvertently create an abnormal path between the subarachnoid space of the brain and nasal/sinus cavities, and accidental trauma is one of them. This fluid has important functions such as cushioning the brain and spinal cord, maintaining intraocular pressure, and cleansing the central nervous system much like the lymphatic system does. Rhinorrhoea could be a devastating condition that can lead to significant morbidity and mortality of the patient. According to a retrospective study, the overall risk of recurrence is $22.5 \%$ in patients who have undergone surgeries either through endonasal or transcranial approach and the recurrence usually presents by either CSF rhinorrhoea or meningitis. ${ }^{[1]}$

The CSF leak at anterior skull base can be managed conservatively by avoidance of straining activity and temporary CSF diversion with serial lumbar punctures or lumbar drains. Surgical repair may be achieved transcranially. However, endoscopic approach in selected cases using autologous materials, such as the fascia lata, free grafts of middle turbinate mucoperichondrium, and septal cartilage grafts, offers a good viewing of surgical field and also allows to manage even larger lesions with minimal invasion. ${ }^{[2]}$ Initial conservative trail can be started and if it fails then on-lay dural technique followed by fibrin glue application through transcranial approach has good outcome with less chances of complications. ${ }^{[3]}$

Patients with post-traumatic CSF rhinorrhoea can also develop meningitis later on. A case of delayed CSF rhinorrhoea, as long as three years after the transfacial gunshot wound, has also been reported. ${ }^{[4]}$ Another case report of an extraordinarily long-term post-traumatic CSF fistula in an adult who presented with frequent clear continuous rhinorrhea and otorrhea for 5 years after basilar skull fracture and later on

\section{Department of Neuroanaesthesiology, All India Institute of Medical Sciences, New Delhi, India}

Address for correspondence:

Dr. Indu Kapoor, Department of Neuroanaesthesiology, Neurosciences Centre, All India Institute of Medical Sciences, New Delhi - 110029 , India.

E-mail: dr.indu.me@gmail.com 


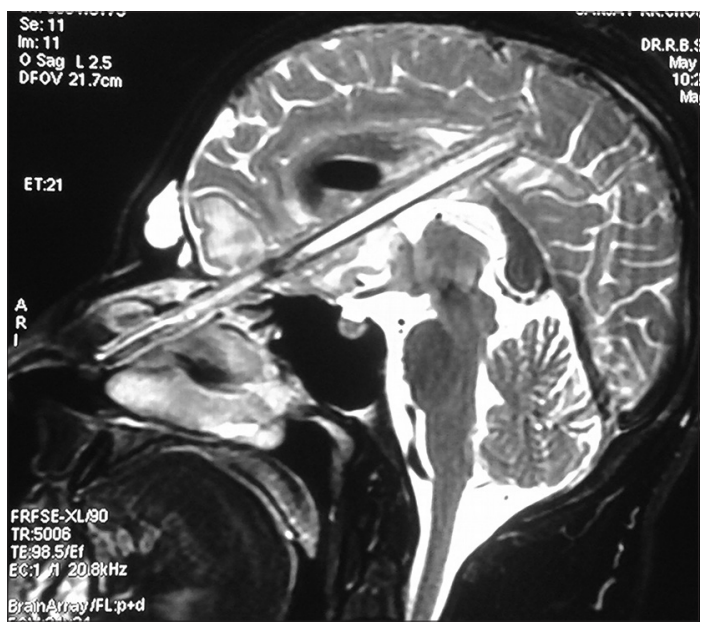

Figure 1: A $13 \mathrm{~cm}$ long tract with surrounding haemorrhage, oedema and intense enhancement extending from the left side of nostril to left high paramedian brain parenchyma through the skull base and ethmoidal sinus which extends above the level of corpus callosum

developed meningitis, has also been reported..$^{[5]}$ CSF rhinorrhoea and otorrhoea are independent predictors of posttraumatic meningitis. ${ }^{[6]} \mathrm{A}$ systemic review of meningitis associated with transsphenoidal surgery done in the past has found that Gram-negative meningitis is associated with transsphenoidal surgery. ${ }^{[7]}$

The possibility of CSF leakage into the orbit in patients who present with post-traumatic CSF rhinorrhoea is high. ${ }^{[8]}$ Hence, a careful monitoring of clinical signs and a follow-up radiography would be mandatory for patients with craniocerebral trauma despite a lack of the definite symptoms. It is also important to rule out the possibility of pseudo-CSF rhinorrhoea in patients with post-traumatic CSF rhinorrhoea, which results from injury to preganglionic parasympathetic fibers supplying the sphenopalatine ganglion. This can be treated with topical medicines such as anticholinergics, and the surgical procedures aimed at disruption of parasympathetic preganglionic fibers proximal to or at the sphenopalatine ganglion. ${ }^{[9]}$

In our case, the bony defect was in the cribriform plate from where the foreign body has entered the brain parenchyma. As discussed earlier, this patient presented to us very late. The initial CT scan was not available, and there was no obvious evidence of foreign body. The only significant history was insertion of Ryle's tube and its removal after failed feeding trial. In the absence of CT scan, we assumed the Ryle's tube as the main cause of rhinorrhoea. However, the foreign body was removed through a mini craniotomy rather than going for the endoscopic transnasal approach, which is considered to be less invasive. The important message is that one should never put a Ryle's tube through the nose in a patient with history of head injury, especially when the scans are not

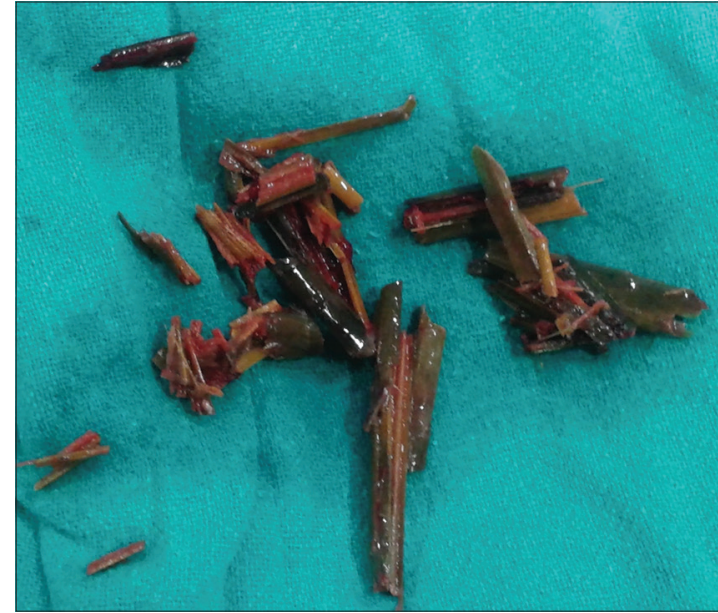

Figure 2: Small pieces of bamboo stick

available to rule out the skull base fracture. A thorough history, clinical examination, and a proper radiographical reporting also play important roles in such cases.

\section{REFERENCES}

1. Schoentgen C, Henaux PL, Godey B, Jegoux F. Management of post-traumatic cerebrospinal fluid (CSF) leak of anterior skull base: 10 years experience. Acta Otolaryngol 2013;133:944-50.

2. GiovannettiF, Ruggeri A, Buonaccorsi S, Pichierri A, ValentiniV. Endoscopic endonasal approaches for cerebrospinal fluid leaks repair. J Craniofac Surg 2013;24:548-53.

3. Aurangzeb A, Ahmed E, Khan SA, Ali A, Ihsan A, Mehmood S. Outcome of transcranial repair of traumatic CSF rhinorrhea. J Ayub Med Coll Abbottabad 2012;24:47-9.

4. Yildirim AE, Dursun E, Divanlioglu D, Ozdol C, Nacar OA, Corapci OE, et al.Unusual posttraumatic delayed cerebrospinal fluid rhinorrhea due to gunshot wound. Turk Neurosurg 2014;24:276-80.

5. Kim HS, Hur JW, Lee JW, Lee HK. Extraordinarily Kim longterm posttraumatic cerebrospinal fluid fistula. J Korean Neurosurg Soc 2007;42:403-5.

6. Sonig A, Thakur JD, Chittiboina P, Khan IS, Nanda A. Is posttraumatic cerebrospinal fluid fistula a predictor of posttraumatic meningitis? A US Nationwide Inpatient Sample database study. Neurosurg Focus 2012;32:E4.

7. Haile-Mariam T, Laws E, Tuazon CU.Gram-negativemeningitis associated with transsphenoidal surgery: Case reports and review. Clin Infect Dis 1994;18:553-6.

8. Rha EY, KimJH, Byeon JH.Posttraumatic delayed cranio-orbital cerebrospinal fluid leakage: Case report. J Plast Reconstr Aesthet Surg 2013;66:563-5.

9. HilinskiJM,Kim T,HarrisJP.Posttraumaticpseudo-cerebrospinal fluid rhinorrhea. Otol Neurotol 2001;22:701-5.

\begin{tabular}{|l|l|}
\hline \multicolumn{2}{|c|}{ Access this article online } \\
\hline Quick Response Code: & Website: \\
\hline & www.jnaccjournal.org \\
\cline { 2 - 2 } & \\
\hline
\end{tabular}

